\title{
Team-Based Learning and Lecture-Based Learning: Comparison of Sudanese Medical Students' Performance
}

\author{
Karim Eldin M A Salih (iD) ${ }^{1-3}$ \\ El-Fatih Z El-Samani ${ }^{4, \dagger}$ \\ Jalal Ali Bilal ${ }^{5}$ \\ Emtinan $\mathrm{K} \mathrm{Hamid}^{6}$ \\ Omer Abdelgadir Elfaki ${ }^{7}$ \\ Muawia EA Idris (D) \\ Hind A Elsiddig (iD ${ }^{8}$ \\ Maha M Salim ${ }^{8}$ \\ Hashim Missawi ${ }^{9}$ \\ Mohammed Abass (D) 10 \\ Walyeldin Elfakey (iD)
}

\begin{abstract}
'Department of Pediatrics, Faculty of Medicine, University of Bahri, Khartoum, Sudan; ${ }^{2}$ Department of Pediatrics, College of Medicine, University of Bisha, Bisha, Saudi Arabia; ${ }^{3}$ Department of Medical Education, College of Medicine, University of Bisha, Bisha, Saudi Arabia; ${ }^{4}$ Department of Community Medicine, School of Medicine, Ahfad University for Women, Khartoum, Sudan; ${ }^{5}$ Department of Pediatrics, College of Medicine, Shaqra University, Shaqra, Saudi Arabia;

${ }^{6}$ Department of Community Medicine,

Faculty of Medicine, University of

Khartoum, Khartoum, Sudan

${ }^{7}$ Department of Internal Medicine and Medical Education Unit, Al-Rayan Medical

Colleges, Medina Munawara, Saudi

Arabia; ${ }^{8}$ Department of Pathology,

Faculty of Medicine, University of Bahri,

Khartoum, Sudan; ${ }^{9}$ Department of

Pathology, Maternity and Children Hospital, Medina Munawara, Saudi Arabia; ${ }^{10}$ Department of Pediatrics, College of Medicine, Arabian Gulf University, Manama, Bahrain

${ }^{\dagger}$ El-Fatih Z. El-Samani passed away on 23. 12.2020
\end{abstract}

Correspondence: Walyeldin Elfakey Department of Pediatrics, Faculty of

Medicine, University of Bahri, Po Box: 1660,

Khartoum, Sudan

$\mathrm{Tel}+249912364272$

Fax +249I55888 406

Email Walyeldina@aol.co.uk
Aim: Students' performance in TBL compared to LBL needs to be evaluated. This study aimed to compare students' performance in team-based learning and traditional lectures.

Methods: A total of 176 class 4 and 202 class 6 medical students from University of Bahri, Khartoum, Sudan, participated in the study during 2018. Experienced staff were selected to conduct the teaching and assessment of the two groups, using the standard team-based learning procedure (iRAT, gRAT and AppT) in the first topic and the lecture-based learning procedure in the second, within the same time limit for the two methods.

Results: The two classes overall mean score has a significant 5.1 points difference $(\mathrm{p}<0.001$; $95 \%$ CI: $3.5,6.0$ ). Separate analysis showed consistency of superiority of TBL to LBL in either gender. A remarkable difference was observed when we compared the two methods in class 6 separately from class 4. Class 6 mean score was high for both TBL and LBL (77.2 and 70.2, respectively), with a significant mean difference of 7.0 ( $\mathrm{p}<0.001 ; 95 \% \mathrm{CI}: 5.1,8.9)$. In class 4 , the score was lower for both methods (mean of 62.8 for TBL and 59.9 for LBL). The mean difference of 2.95 points was still significant $(\mathrm{p}<0.05 ; 95 \%$ CI: $0.46,5.43)$. Separate multivariate linear regression for TBL and LBL showed no significant difference in performance of males and females in either method. Controlling for gender in TBL, class 4 had a mean of -14.26 points, $(\mathrm{p}<0.001 ; 95 \% \mathrm{CI}:-12.54,-15.98)$ less than class 6 . Similarly, in LBL, class 4 had a mean of -10.18 points ( $p<0.001,95 \%$ CI: $-7.02,-13.35)$, less than class 6.

Conclusion: Students' performance using team-based learning was superior to lecturebased learning, irrespective of students' gender, noticeable among senior students.

Keywords: team-based learning, lecture-based curriculum, medical education, curriculum, assessment

\section{Introduction}

The popularity of team-based learning (TBL) among students could be due to many reasons: first, deep learning is established; second, it encourages self-directed learning and avoids just memorization; and lastly, it prepares students to solve problems and fosters teamwork. ${ }^{1,2}$ Although traditional lecture-based learning (LBL) is needed for large groups, team-based learning can be used with large groups, especially when materials are available to students, which promotes critical thinking and encourages teamwork. ${ }^{3-5}$ Evidence-based studies support the use of self-directed learning, which could be more beneficial than just giving lectures to provide knowledge. ${ }^{6,7}$ Many authors consider student performance in TBL to be the 
same as that in traditional lectures ${ }^{8,9}$; however, other advantages of TBL could outmatch traditional LBL, for instance in prior knowledge before the class, splitting a large group into small groups without requiring an increased number of faculty, students taking responsibility for their own learning, and enhanced tutor-student relationships. ${ }^{10-13}$ TBL has three steps. Initially, students must work on their reading assignment on a topic chosen by their tutor, who provides references or reading materials based on a timetable. Then on the TBL day, each student immediately answers usually 10 MCQs (ie, individual readiness assurance test [iRAT]). Immediately after that, the same MCQs are answered by a predetermined group (ie, team readiness assurance test (gRAT), then usually five new MCQs are answered by all groups. This final test is called application test (AppT). When all these processes are finished, the students and the tutor discuss the answers to the questions, and finally, the tutor gives a micro lecture. ${ }^{12,14-18}$

Rationale: In countries with a setup that is similar to ours, where the number of students is increasing and there is shortage of faculty and facilities, TBL may provide an alternative option for assessment as well as teaching strategy to improve learning in medical schools.

Objectives of this study: to compare student performance in team-based learning and that in traditional lecture-based learning, where TBL is possible in both preclinical and clinical phases.

Our research question is whether there are any differences in student performance between team-based learning and traditional lecture-based learning, ie, is peer performance is better than individual performance.

\section{Methods}

\section{Study Design, Setting, and Participants}

Participants in this intervention study were fourth-year and sixth-year medical students at University of Bahri in Khartoum, Sudan, during the academic year 2018-2019. The university implements a curriculum that uses different teaching strategies, but mainly lectures and a hybrid problem-based learning (PBL). The fourth-year students $(n=225)$ have passed the preliminary basic sciences of anatomy, physiology, and biochemistry; and the study was conducted in the pathology course. The sixth-year students $(n=220)$, on the other hand, have completed all the basic sciences, and enrolled in major clinical courses. The experts based the selection for sixth- and fourth-year students for the study on the following assumption. The fourth year in the midway after intermediate and can reasonably judges what learning methodology will fit them rather than second- or third-, while sixth-year students can be in a better position to tell which is the best after they finished their presumed program. The study was conducted on their pediatrics course. All the students had no previous experience with TBL, but they were familiar with lectures.

\section{Procedure}

The students from both classes were oriented in advance about TBL and traditional lectures as educational interventions. The study objectives were explained to them, and it was made clear that their participation was optional. Two specialized faculty members conducted the orientation about TBL in both classes. The students who opted to participate in the study were 176 from class 4 and 202 from class 6 with a response rate of $78.2 \%$ and $91.8 \%$, respectively.

\section{TBL Intervention}

The objectives and contents for the topic of nephrotic syndrome were explained to all the sixth-year students participating in the study using PowerPoint slides and pamphlets. The pathology of skin tumors was explained in the same manner to the fourth-year students. TBL was used for over 2 hours in both classes. The students did their reading 1 week before the TBL workshop, and then at a specified day, each student answered the individual readiness assurance test (iRAT). The tutor then randomly divided class 4 students into 10 groups and class 6 students into 8 . Then, the students answered the same test in consensus as a group (gRAT). After collecting the answer sheets from both tests, the tutor administered the application test, where the groups were given cards that contained answer choices and the correct answer card would be raised by each group after the discussion and then the tutor would record the results and assign scores to each group. This was labeled as Application Test (AppT).

\section{LBL Intervention}

In the lecture-based intervention, different topics were selected: sickle cell anemia for class 6 students and brain tumors for class 4 students. The same TBL tutor delivered the lecture for the two classes and spent the same period of time as for TBL. The lectures were conducted as conventional ones using visual aids in the form of a PowerPoint 
presentation, emphasizing the objectives and encouraging the students to ask questions. Then, the students were asked to individually answer the test (TrT).

\section{Measuring Outcome}

The iRAT, gRAT, and AppT scores were used to measure the outcome of the students' learning when the TBL intervention was used, whereas the TrT score was used to measure the learning outcome when the traditional lecture intervention was used. The total score for iRAT was 50, that for gRAT was 30, and that for AppT was 20, collectively making a total score of 100 (total TBL). The outcome for the traditional lecture-based learning was measured using a test with a total score of 100 . The tests consisted of questions with a scenario-based, single best correct answer. All the students were not aware that the questions for iRAT, gRAT, and AppT were the same but arranged in different orders.

\section{Statistical Analysis}

Data were coded, entered, summarized and analyzed using SPSS software version 21. Categorical and nominal variables were expressed as frequencies and percentages. The Shapiro-Wilk test was used to test the normal distribution of the test scores. Paired sample $t$-test and linear regression were used to compare quantitative data. A p-value of $<0.05$ was considered significant.

\section{Results}

A reliability analysis was carried out on the 4 test scores for TBL, iRAT, gRAT and Appt, and the total summation of all of them (total TBL). Cronbach's $\alpha$ showed that the different modalities of TBL test scores had acceptable reliability, $\alpha=0.69$. A lower, however acceptable, value of reliability (Cronbach's $\alpha=0.58$ ) was obtained when the analysis was carried out on the 10 test scores altogether including scores for LBL. Most tests seemed worth of retention because alpha value was decreased when any of the tests were deleted from the items' total statistics.

The overall performance results showed a mean score of 70.5 for TBL and 65.4 for LBL in the combined class 4 and class 6 . The mean difference in scores (5.0 marks) was significant $(p<0.001,95 \%$ CI: $3.5,6.0)$. The histogram (with moderate skewing to the left) showed that many more students failed to score above $60 \%$ in LBL compared to TBL (Figure 1).

We performed analyses for all the females (312) and all the males (66) separately and observed a consistency of
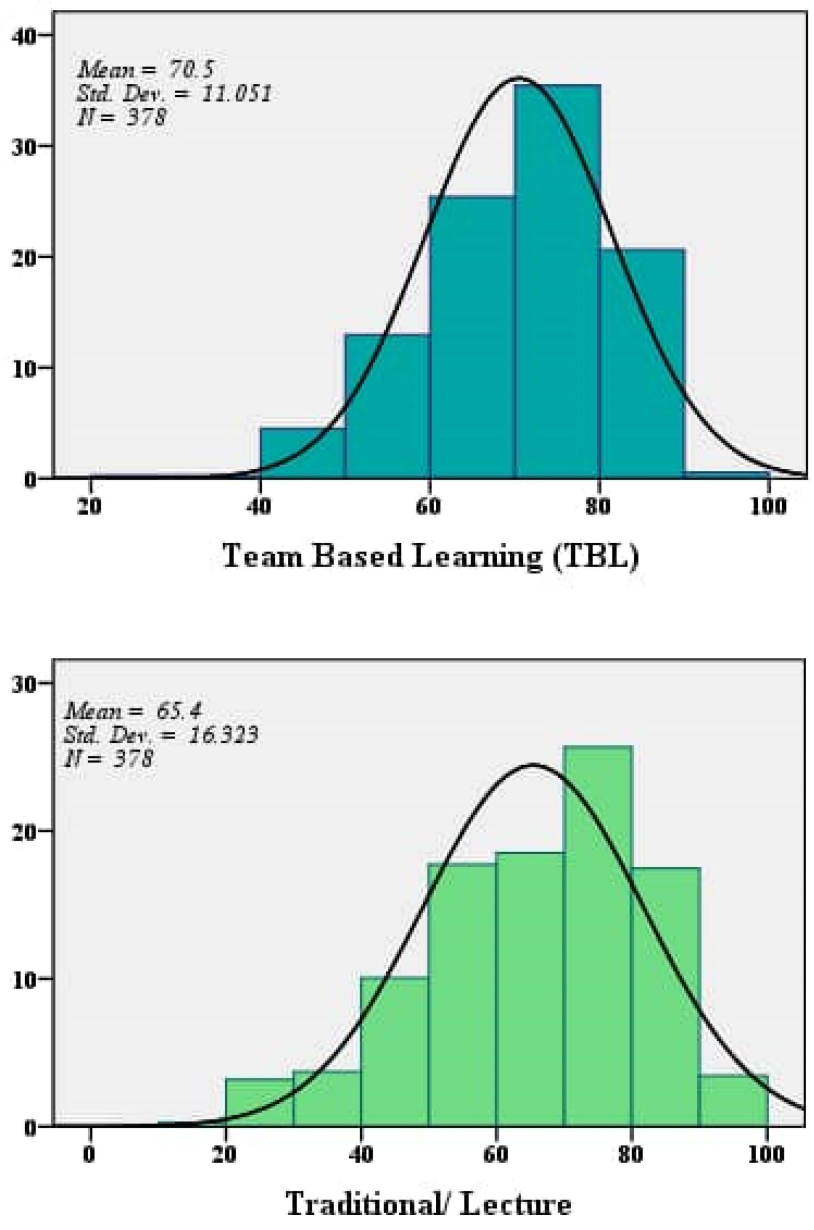

Figure I Comparison of students' scores in the tests following TBL and LBL.

the superiority of TBL to LBL in either gender. The mean score was 71.0 for TBL and 66.0 for LBL in the female classes with a mean difference of 5.1 (p-value $<0.001$, $95 \%$ CI: 3.3, 6.8). Male classes, on the other hand, showed a slightly lower mean score in both TBL (68.1) and LBL (62.8). Nevertheless, the mean difference of 5.3 points, was significant ( $\mathrm{p}<0.001,95 \%$ CI: 2.1, 8.5), Table 1 .

A remarkable difference in the results was observed when we compared the two methods in class 6 separately from class 4 . The class 6 mean score was high for both TBL and LBL (77.2 and 70.2, respectively) with a significant mean difference of 7.0 points $(p<0.001$, 95\% CI 5.1, 8.9). In class 4 , the score was lower for both methods (mean 62.8 for TBL and 59.9 for LBL). The mean difference was $2.95(\mathrm{p}<0.05 ; 95 \%$ CI: 0.46 , 5.43), as shown in Table 2.

We performed a stratified analysis to compare the differences in the mean scores of the two methods by gender and class. The mean scores and difference continued to be highly 
Table I Paired $t$-Test Comparing Scores of TBL and LBL Among Male $(n=66)$ and Female $(n=3 \mid 2)$ Students

\begin{tabular}{|c|c|c|c|c|c|c|}
\hline \multirow[t]{2}{*}{ Variable } & \multicolumn{2}{|c|}{ Mean } & \multicolumn{2}{|c|}{ Standard Error } & \multicolumn{2}{|c|}{$95 \% \mathrm{Cl}$} \\
\hline & $M$ & $\mathbf{F}$ & $\mathbf{M}$ & $\mathbf{F}$ & $M$ & $\mathbf{F}$ \\
\hline TBL & 68.1 & 71.02 & 1.3 & 0.63 & $65.4-70.7$ & $69.78-72.25$ \\
\hline LBL & 62.8 & 65.96 & 1.9 & 0.93 & $59.0-66.5$ & $64.13-67.80$ \\
\hline Difference & 5.3 & 5.05 & 1.6 & 0.89 & $2.1-8.5$ & $3.29-6.81$ \\
\hline Paired $t$-test & 3.3 & 5.6 & & & & \\
\hline 2-Sided $P$ value & $<0.01$ & $<0.001$ & & & & \\
\hline
\end{tabular}

Abbreviations: $\mathrm{Cl}$, confidence interval; TBL, team-based learning; LBL, lecture-based learning; M, male; F, female.

Table 2 Paired $t$-Test Comparing Scores of TBL and LBL Among Students of Class $6(n=202)$ and Class $4(n=I 76)$

\begin{tabular}{|l|c|c|c|c|c|c|}
\hline \multirow{2}{*}{ Variable } & \multicolumn{2}{|c|}{ Mean } & \multicolumn{2}{c|}{ Standard Error } & \multicolumn{2}{c|}{$95 \%$ CI } \\
\cline { 2 - 7 } & Class 6 & Class 4 & Class 6 & Class 4 & Class 6 & Class 4 \\
\hline TBL & 77.18 & 62.84 & 0.41 & 0.80 & $76.37-77.99$ & $61.25-64.42$ \\
\hline LBL & 70.21 & 59.89 & 1.01 & 1.26 & $68.22-72.20$ & $57.39-62.38$ \\
\hline Pifference & 6.97 & 2.95 & 0.97 & 1.26 & $5.05-8.88$ & $0.46-5.43$ \\
\hline 2-Sided P value & 7.16 & 2.34 & & & & \\
\hline
\end{tabular}

Abbreviations: TBL, team-based learning; LBL, lecture-based learning.

significant for both the females and the males in class 6 . Females scored 77.4 and 70.5 in TBL and LBL, respectively, with mean difference 6.7 ( $p<0.001,95 \%$ CI: 4.8, 9.0), while males scored 76.0 and 68.7 in TBL and LBL respectively with mean difference 7.3 ( $p<0.01,95 \%$ CI: $2.8,11.8)$. The mean scores and the difference in the mean scores in class 4 was not significant for the females (mean difference 2.7; $\mathrm{p}=0.07,95 \% \mathrm{CI}:-0.22,5.64)$, nor was it significant for the males (mean difference $3.82 ; \mathrm{p}=0.10,95 \% \mathrm{CI}$ : -0.79 , 8.42).

To control any confounding effect of gender and class on student performance, we used a multivariate linear regression model to estimate the mean expected performance of TBL and LBL. The estimated mean score for LBL was 59.1 (95\% CI: 57.5, 60.8) for a female in fourth Class. Males scored an average of 1.5 points less than females but were not significant. On average, students scored 12.2 points more if they were in class 6 compared to class 4 (95\% CI: 10.4, 14.0, $p<$ 0.001). While controlling the effect of gender and class, students scored an average of 5.1 points higher when taught through TBL, compared to LBL (95\% CI: 3.3, $6.9, p<0.001)$, Table 3.
Table 3 Multiple Linear Regression for Expected Performance Score

\begin{tabular}{|l|c|c|c|c|c|}
\hline Model & \multicolumn{2}{|c|}{ Coefficients } & \multirow{2}{*}{$\boldsymbol{P}$} & P value & $\begin{array}{c}95.0 \% \\
\text { Confidence } \\
\text { Interval }\end{array}$ \\
\cline { 2 - 5 } & B & $\begin{array}{c}\text { Standard } \\
\text { Error }\end{array}$ & & & \\
\hline Constant* & 59.1 & 0.85 & 69.7 & $<0.001$ & 57.5 to 60.8 \\
Gender & -1.5 & 1.20 & -1.2 & 0.229 & -3.8 to 0.9 \\
Class & 12.2 & 0.92 & 13.3 & $<0.001$ & 10.4 to 14.0 \\
Method & 5.1 & 0.91 & 5.6 & $<0.001$ & 3.3 to 6.9 \\
\hline
\end{tabular}

Notes: Gender: Male $=$ I, Female $=0$; Class: 6 th $=$ I, 4th $=0$; Method: TBL $=$ I, $\mathrm{LBL}=0 .{ }^{*}$ Constant $=$ mean score of fourth-class female student in $\mathrm{LBL}$.

\section{Discussion}

To the best of our knowledge, this is the only available study in Sudan that outlines the quality of student performance in TBL versus traditional lecturing. TBL was consistently superior in student performance to LBL, irrespective of the gender of the students, as there was no significant difference in performance by gender, in either class. More students in TBL scored higher marks. However, this higher TBL performance was evident in class 6 . It seems that TBL is more stable and beneficial to senior medical students. Perhaps, it 
required students who are more experienced and independent learners, as well as team workers with a greater sense of responsibility toward their academic work. These findings could be explained by the good preparation before the test, which affects performance in iRAT, and the collaboration among the team members during gRAT. In fact, several studies have documented that students performed better in TBL than in LBL, ${ }^{19,20}$ the results of the study of Reagans, Argote, and Brooks (2005), who used authentic TBL in the workplace. ${ }^{21}$ Also, this study is in harmony with that of Edmondson, Winslow, Bohmer, and Pisano (2003), who reported that TBL enhances knowledge among team members. ${ }^{22}$ It is consistent with study done among medical students (males and females) at the Boonshoft School of Medicine (2004-2005), which adopted a curriculum similar to that of the University of Bahri's College of Medicine. ${ }^{23}$ The findings here are similar with the study done among medical students at Wright State University when their performance by TBL was compared to that of students who took the traditional method of teaching. ${ }^{24}$ There was correspondence with study on dental students at the University of Florida which showed that students who received knowledge through TBL did well in their examination and retained knowledge for a long time, which allowed them to do well in the workplace compared to learning through traditional LBL. ${ }^{25}$ Our study is analogous with those of Yan et al, at the Medical School of Chifeng in the People's Republic of China, which reported higher TBL examination scores compared with traditional lecture examination scores $(81.70$ \pm 8.53 vs $74.41 \pm 8.27, p<0.01)$ and higher marks reported in TBL compared with those in LBL and conventional tutorial (CT) groups as shown in Hashilkar. ${ }^{25,26}$ There is some resemblance with the results of an Indian study conducted on students from a college of pharmacology. ${ }^{27}$ Finally, it is obvious that TBL supports collaborative learning through teams, which is reflected by different studies. ${ }^{28}$

While in our setup senior students performed better than junior ones, still, our junior students performed well in TBL, which is comparable to the findings of other studies. ${ }^{29}$ TBL, with the higher performance, compared with traditional lectures, will set a high standard, a factor that could ensure social accountability and good quality of doctors. ${ }^{30-33}$ Our study showed that females and males performed similarly, in TBL and LBL. The slightly higher scores of females in both methods were not statistically significant. However, at Maulana Azad Medical College in India, TBL was observed to be an effective learning tool for females and high achievers. ${ }^{18,29,34}$ The findings that TBL was superior to traditional lectures are supported by many studies; however, this depends on students' positive perception of TBL, ${ }^{35}$ interaction between students, changing experiences among students and the collaborative nature of TBL, ${ }^{28}$ enhanced communication, professionalism, self-directed learning, critical thinking, and knowledge application. ${ }^{30}$ Finally, recent studies by many authors support this study, pointed out the valuable advantages of it and recommended it for implantation in learning. ${ }^{36-39}$

\section{Limitations}

This comparison of student performance through exposures to TBL and LBL was based on the assessment of each group using iRAT, gRAT, Appt for TBL and classical assessment for LBL (MCQs, etc). A true difference in performance can only be evaluated if graduates who are products of the two methods were assessed using a standard assessment for both educational techniques. Later in service, evaluation could reflect how much knowledge and skills were retained from being trained using these two different educational methods. Moreover, this comparison was only made on selected topics in only two disciplines rather than on full courses, besides large number of the small groups. In this paper, we did not study the student perspectives and we recommend further studies to consider this point.

\section{Conclusion}

Medical students' performance using team-based learning was consistently superior to traditional lecture-based learning, irrespective of students' gender. Senior medical students scored better than junior students following team-based learning. The study highlighted a solution to an educational process in countries with low resources.

\section{Ethical Approval and Consent}

The ethical approval of the study was obtained from the University of Bahri Research and Ethical Committee (UBREC). All participants have provided written informed consent. This study complies with the Declaration of Helsinki.

\section{Acknowledgments}

The authors would like to share condolences with all colleagues and reader for the sad death of our senior coauthor Professor Elfatih Elsamani, who pass away during the preparation and submission of this manuscript, due to COVID-19 and special condolences to his family and students, without his meticulous hands on and guidance 
this work might not be materialized. At this juncture, the authors would like to convey their appreciation to the students who agreed to participate in this study, $\mathrm{Mr}$ Ayman Elshayeb for editing our references and Madam Fadia for her great work in data entry.

\section{Author Contributions}

All authors made a significant contribution to the work reported, whether that is in the conception, study design, execution, acquisition of data, analysis and interpretation, or in all these areas; took part in drafting, revising or critically reviewing the article; gave final approval of the version to be published; have agreed on the journal to which the article has been submitted; and agree to be accountable for all aspects of the work.

\section{Disclosure}

The authors report no conflicts of interest in this work.

\section{References}

1. Garland D. Assessment issues in group work. In: Foot HC, Howe CJ, Anderson A, Tolmie A, Warden D, editors. Group and Interactive Learning. Southampton: Computational Mechanics Publications; 1994:417-422.

2. Tribe D. An overview from higher education. In: Thorley L, Gregory R, editors. Using Group-Based Learning in Higher Education. London: Cogan Page; 1994:25-36.

3. Acrreditation Councel for Pharmacy Education (ACPE). Accreditation standards and guidelines for the professional program in pharmacy leading to the doctor of pharmacy degree. Chicago; 2011.

4. Jensen E. Brain-Based Learning: The New Paradigm of Teaching. Thousand Oaks, CA: Corwin Press; 2008.

5. Persky AM, Pollack GM. A modified team-based learning physiology course. Am J Pharm Educ. 2011;75(10):204. doi:10.5688/ajpe7510204

6. Bligh D. What's the Use of Lectures? 1st ed. San Francisco: JosseyBass; 2000.

7. Murad MH, Coto-Yglesias F, Varkey P, Prokop LJ, Murad AL. The effectiveness of self-directed learning in health professions education: a systematic review. Med Educ. 2010;44(11):1057-1068. doi:10.1111/j.1365-2923.2010.03750.x

8. Bleske BE, Remington TL, Wells TD, et al. Team-based learning to improve learning outcomes in a therapeutics course sequence. $\mathrm{Am}$ J Pharm Educ. 2014;78(1):13. doi:10.5688/ajpe78113

9. Fatmi M, Hartling L, Hillier T, Campbell S, Oswald AE. The effectiveness of team-based learning on learning outcomes in health professions education: BEME Guide No. 30. Med Teach. 2013;35(12): e1608-24.

10. Ofstad W, Brunner LJ. Team-based learning in pharmacy education. Am J Pharm Educ. 2013;77(4):70. doi:10.5688/ajpe77470

11. Frame TR, Cailor SM, Gryka RJ, Chen AM, Kiersma ME, Sheppard L. Student perceptions of team-based learning vs traditional lecture-based learning. Am J Pharm Educ. 2015;79(4):51. doi:10.5688/ajpe79451

12. Nelson M, Allison SD, McCollum M, et al. The Regis model for pharmacy education: a highly integrated curriculum delivered by Team-Based Learning (TBL). Curr Pharm Teach Learn. 2013;5 (6):555-563. doi:10.1016/j.cpt1.2013.07.002
13. Kelly PA, Haidet P, Schneider V, Searle N, Seidel CL, Richards BF. A comparison of in-class learner engagement across lecture, problem-based learning, and team learning using the STROBE classroom observation tool. Teach Learn Med. 2005;17(2):112-118. doi:10.1207/s15328015tlm1702_4

14. Allen RE, Copeland J, Franks AS, et al. Team-based learning in US colleges and schools of pharmacy. Am J Pharm Educ. 2013;77 (6):115. doi:10.5688/ajpe776115

15. Jungnickel PW, Kelley KW, Hammer DP, Haines ST, Marlowe KF. Addressing competencies for the future in the professional curriculum. Am J Pharm Educ. 2009;73(8):156. doi:10.5688/aj7308156

16. Addo-Atuah J. Performance and perceptions of pharmacy students using team-based learning (TBL) within a global health course. Innov Pharm. 2011;2(2). doi:10.24926/iip.v2i2.220

17. Rezende AB, de Oliveira AG, Vale TC, et al. Comparison of team-based learning versus traditional lectures in neuroanatomy: medical student knowledge and satisfaction. Anat Sci Educ. 2020;13(5):591-601. doi:10.1002/ase.1926

18. Isbell JA, Makeeva V, Caruthers K, Brooks WS. The impact of TeamBased Learning (TBL) on physician assistant students' academic performance in gross anatomy. $J$ Physician Assist Educ. 2016;7 (3):126-130. doi:10.1097/JPA.0000000000000082

19. Martínez EG, Tuesca R. Modified team-based learning strategy to improve human anatomy learning: a pilot study at the Universidad del Norte in Barranquilla, Colombia. Anat Sci Educ. 2014;7 (5):399-405. doi:10.1002/ase.1444

20. Edmondson ACDJ, Dillon JR, Roloff,KS. 6 three perspectives on team learning: outcome improvement, task Mastery, and group process. Acad Manag Ann. 2007;1(1):269-314. doi:10.5465/ 078559811

21. Edmondson AC, Winslow AB, Bohmer RM, Pisano GP. Learning how and learning what: effects of tacit and codified knowledge on performance improvement following technology adoption. Decis Sci. 2003;34(2):197-224. doi:10.1111/1540-5915.02316

22. Koles PG, Stolfi A, Borges NJ, Nelson S, Parmelee DX. The impact of team-based learning on medical students' academic performance. Acad Med. 2010;85(11):1739-1745. doi:10.1097/ACM.0b013e3181f52bed

23. Koles P, Nelson S, Stolfi A, Parmelee D, Destephen D. Active learning in a year 2 pathology curriculum. Med Educ. 2005;39 (10):1045-1055. doi:10.1111/j.1365-2929.2005.02248.x

24. Echeto LF, Sposetti V, Childs G, et al. Evaluation of team-based learning and traditional instruction in teaching removable partial denture concepts. J Dent Educ. 2015;79(9):1040-1048. doi:10.1002/ j.0022-0337.2015.79.9.tb05997.x

25. Yan J, Ding X, Xiong L, et al. Team-based learning: assessing the impact on anatomy teaching in People's Republic of China. Adv Med Educ Pract. 2018;9:589-594. doi:10.2147/AMEP.S169949

26. Hashilkar N, Getula M, Ameen A. Effectiveness of team based learning to teach pharmacology for phase-II MBBS students. $J$ Med Sci. 2014;7:181-187.

27. Michaelsen LK, Sweet M. Fundamental principles and practices of team-based learning. In: Michaelsen L, Parmelee D, McMahon K, Levine R, editors. Team-Based Learning for Health Professions Education: A Guide to Using Small Groups for Improving Learning. Sterling, Virginia: Stylus Publishing; 2012:9-34.

28. Cevik AA, ElZubeir M, Abu-Zidan FM, Shaban S. Team-based learning improves knowledge and retention in an emergency medicine clerkship. Int J Emerg Med. 2019;12(1):6. doi:10.1186/s12245019-0222-2

29. Park SE, Salihoglu-Yener E, Fazio SB. Use of team-based learning pedagogy for predoctoral teaching and learning. Eur J Dent Educ. 2019;23(1):32-36. doi:10.1111/eje.12396

30. Ding C, Li S, Chen B. Effectiveness of flipped classroom combined with team-, case-, lecture- and evidence-based learning on ophthalmology teaching for eight-year program students. BMC Med Educ. 2019;19(1):419. doi:10.1186/s12909-019-1861-y 
31. Jakobsen KV, Daniel DB. Evidence-inspired choices for teachers: team-based learning and interactive lecture. Teach Psychol. 2019;46 (4):284-293. doi:10.1177/0098628319872411

32. Das S, Nandi K, Baruah P, Sarkar SK, Goswami B, Koner BC. Is learning outcome after team based learning influenced by gender and academic standing? Biochem Mol Biol Educ. 2019;47(1):58-66. doi:10.1002/bmb. 21197

33. Mlika M, Charfi R, Cheikhrouhou S, Mezni F. About the association of a lecture-based learning and team-based learning in a pathology course. Ann Pathol. 2020;40(4):329-336. doi:10.1016/j.annpat.201 9.11.004

34. Calleja JL, Soublette Sanchez A, Radedek Soto P. Is clinical simulation an effective learning tool in teaching clinical ethics? Medwave. 2020;20(2):e7824. doi:10.5867/medwave.2020.01.7824

35. Senkoylu A, Senkoylu B, Budakoglu I, Coskun O, Acaroglu E. Blended learning is a feasible and effective tool for basic pediatric spinal deformity training. Global Spine J. 2020;11(2):219-223. doi: $10.1177 / 2192568220916502$
36. Wang L, Khalaf AT, Lei D, et al. Structured oral examination as an effective assessment tool in lab-based physiology learning sessions. Adv Physiol Educ. 2020;44(3):453-458.

37. Bormann CL, Kanakasabapathy MK, Thirumalaraju P, et al. Performance of a deep learning based neural network in the selection of human blastocysts for implantation. Elife. 2020;9:e55301.

38. Thivilliers AP, Ladarre R, Merabti O, et al. The learning curve in transcatheter aortic valve implantation clinical studies: a systematic review. Int J Technol Assess Health Care. 2020;36(2):152-161. doi:10.1017/S0266462320000100

39. Datta G, Durbin K, Odell A, Ramirez-Inscoe J, Twomey T. The development and implementation of the Nottingham early cognitive and listening links (Early CaLL); A framework designed to support expectation counselling and to monitor the progress, post cochlear implantation, of deaf children with severe (SLD) and profound and multiple learning difficulties (PMLD) and associated complex needs. Cochlear Implants Int. 2020;21(1):18-34. doi:10.1080/1467010 0.2019 .1662586

\section{Publish your work in this journal}

Advances in Medical Education and Practice is an international, peerreviewed, open access journal that aims to present and publish research on Medical Education covering medical, dental, nursing and allied health care professional education. The journal covers undergraduate education, postgraduate training and continuing medical education including emerging trends and innovative models linking education, research, and health care services. The manuscript management system is completely online and includes a very quick and fair peer-review system. Visit http://www.dovepress.com/testimonials.php to read real quotes from published authors. 